\title{
ANÁLISE COMPARATIVA DAS AVALIAÇÕES DE DESEMPENHO E SUAS RELAÇÕES COM AS MICROEMPRESAS SOB ENFOQUE MACROERGONÔMICO
}

\section{COMPARATIVE ANALYSIS OF PERFORMANCE ASSESSMENTS AND ITS RELATIONS TO MICROENTERPRISES UNDER A MACROERGONOMIC APPROACH}

\author{
João Cezar Silva Moura ${ }^{1}$, Bel. \\ Flávio Anthero Nunes Vianna dos Santos ${ }^{2}$, D.Sc. \\ (1) UDESC (Universidade do Estado de Santa Catarina) \\ e-mail: joaocezar ba@hotmail.com \\ (2) UDESC (Universidade do Estado de Santa Catarina) \\ e-mail: flavioanvs@hotmail.com
}

\begin{abstract}
Palavras-chave: Análise Comparativa, Avaliação de Desempenho em Microempresas, Macroergonomia
Os presentes estudos têm como objetivo averiguar as relações macroergonômicas entre os diferentes conceitos atribuídos às Avaliações de Desempenho, bem como sua aplicabilidade em microempresas. Para isto, foram coletadas e reunidas as principais características das avaliações segundo os autores mais citados nas bases de dados (periódicos) da Capes, utilizando-se a RBS (Revisão Bibliográfica Sistemática). As análises foram realizadas de acordo com os objetivos, vantagens e demais elementos que auxiliaram na clarificação e entendimento dos processos pelos quais a implementação das Avaliações de Desempenho ocorre. Por fim, foram sintetizados os conteúdos, apontadas as convergências teoréticas e estabelecidas conclusões e inter-relações acerca dos temas discutidos.
\end{abstract}

Key-words: Comparative Analysis, Performance Assessment in Microenterprises, Macroergonomics

The objective of the present studies is to investigate the macroergonomic relationships between the different concepts attributed to Performance Assessments, as well as their applicability in microenterprises. For this, the main characteristics of the evaluations according to the most cited authors in the (periodical) databases of Capes were collected using RBS (Systematic Bibliographic Review). The analyzes were performed according to the objectives, advantages and other elements that aided in the clarification and understanding of the processes by which the implementation of Performance Assessment takes place. Finally, the contents were synthesized, pointing out the theoretical convergences and establishing conclusions and interrelations about the discussed themes. 


\section{Introdução}

As Avaliações de Desempenho são consideradas a prática em que organizações formulam e aplicam testes aos seus colaboradores com o propósito de verificar a performance das funções e atividades realizadas pelos mesmos (FLEURY, 2002). Deste modo, pode-se compreender mais facilmente até que ponto os objetivos do trabalhador se encontram em consonância com os da empresa, tornando-se possível a identificação prematura de problemas e, inclusive, de competências (RABAGLIO, 2010).

No caso das microempresas, a gestão voltada ao acompanhamento de processos e funcionários é inerente à perenidade em mercados cada vez mais próximos e competitivos. As Avaliações de Desempenho exercem, portanto, um papel fundamental no controle e monitoramento da "saúde interna" das empresas, mensurando e garantindo a qualidade de seus serviços e atingimento de metas organizacionais. Neste sentido, os presentes estudos pretendem estabelecer os conceitos e características referentes às $\mathrm{AD}$ (Avaliações de Desempenho) que melhor se adequam às atuais práticas e realidade das microempresas, atendo-se às suas singularidades organizacionais.

A escolha para compilação dos conceitos de cada autor foi feita de acordo com a pertinência e número de citações encontradas na base de dados pesquisada. Para melhor leitura e compreensão dos dados obtidos, estes foram subdivididos nas seguintes categorias:

Conceito (entendimento geral dos fundamentos que constituem a Avaliação de Desempenho);

- Objetivos (principais metas associadas à sua implementação nas organizações);

- Vantagens (benefícios associados às diferentes áreas de uma organização envolvidas no processo). $16^{\circ}$ Ergodesign - Congresso Internacional de Ergonomia e Usabilidade de Interfaces Humano Tecnológica: Produto, Informações Ambientes Construídos e Transporte

$16^{\circ}$ USIHC - Congresso Internacional de Ergonomia e Usabilidade de Interfaces Humano Computador

CINAHPA | 2017 - Congresso Internacional de Ambientes Hipermídia para Aprendizagem.

\section{Referencial Teórico}

\subsection{Macroergonomia}

A Ergonomia (ou Fatores Humanos, como também é conhecida atualmente) é uma ciência holística que trata, de modo geral, da adaptação do trabalho ao homem. Por este motivo, ela reúne informações de disciplinas pertencentes às mais diversas áreas do conhecimento (engenharia, antropometria, administração, psicologia, etc.). Para melhor definição de seus ramos de estudo e atuação, ela é organizada em 3 principais domínios. De acordo com a Associação Internacional de Ergonomia (IEA - International Ergonomics Association), são eles:

- Ergonomia Física - estudo das características anatômicas, antropométricas, fisiológicas e biomecânicas do ser humano;

- Ergonomia Cognitiva - estudo dos processos mentais vinculados à percepção, memória, raciocínio e coordenação motora;

- Macroergonomia - estudo do melhoramento dos sistemas sociotécnicos, incluindo-se suas estruturas organizacionais, políticas e processos.

A Macroergonomia estuda a comunicação e relações entre os diferentes setores (internos e externos) de uma mesma empresa, propiciando as interações entre microprocessos e auxiliando a tomada de decisões estratégicas (IEA, 2016). Neste sentido, as análises conceituais comparativas serão realizadas de acordo com pontos de vista macroergonômicos, avaliando-se o sentido e extensão que determinados conceitos apresentam ao descreverem suas principais características.

\subsection{Avaliações de Desempenho}

As Avaliações de Desempenho podem ser entendidas como um sistema capaz de mensurar a performance de seus avaliados mediante as funções a serem desenvolvidos pelos mesmos, tendo-se como principais parâmetros as metas a serem alcançadas e o modo como as próprias atividades 
$16^{\circ}$ Ergodesign - Congresso Internacional de Ergonomia e Usabilidade de Interfaces Humano Tecnológica: Produto, Informações Ambientes Construídos e Transporte

$16^{\circ}$ USIHC - Congresso Internacional de Ergonomia e Usabilidade de Interfaces Humano Computador

CINAHPA | 2017 - Congresso Internacional de Ambientes Hipermídia para Aprendizagem. devem ser realizadas (CHIAVENATO, 1999). Sua implementação nas organizações viabiliza a identificação não apenas de problemas (tanto internos quanto externos) a serem corrigidos através de treinamentos capacitivos, mas também de potenciais a serem desenvolvidos por meio de promoções e incentivos salariais, objetivando-se melhorias nos resultados organizacionais decorrentes do reconhecimento e desenvolvimento de profissionais comprometidos com a visão e objetivos da empresa (CHIAVENATO, 2001).

As avaliações devem ser formuladas de acordo com as características únicas de cada função e/ou atividade analisada para que seus resultados sejam, de fato, condizentes com o potencial de seus respectivos colaboradores. Segundo Lima, Oliveira Castro e Veiga (1996), "os sistemas de Avaliação de Desempenho devem ser justos e imparciais, baseados em padrões de desempenho atingíveis, objetivos e claros, apoiados na realidade dos cargos ou postos de trabalho".

Para Grillo (1981), "os resultados obtidos por um processo descentralizado são muito mais reais, pois os métodos utilizados melhor respondem às peculiaridades de cada órgão", ou seja, deve-se evitar a formulação de modelos únicos a serem aplicados em diferentes tipos de setores, por exemplo. Isto exige uma compreensão aprofundada de todos os micro processos que ocorrem dentro da empresa, além de uma comunicação intersetorial fluente e horizontal, onde suas repartições possam agir em conjunto, compartilhando informações em prol de um objetivo em comum: o sucesso e perenidade da própria empresa.

Todas estas considerações devem ser previamente comunicadas aos funcionários envolvidos para que os objetivos da avaliação sejam mais facilmente compreendidos e alcançados, evitando-se possíveis equívocos e tendenciosidades. Para Grillo (1981), a Avaliação de Desempenho "fornece elementos capazes de informar sobre a correção do instrumento seletivo, bem como situar as áreas mais carentes de treinamento", identificando os setores onde correções e melhorias se fazem mais urgentes.
Avaliar o desempenho humano tem sido uma atividade intrínseca às interações sociais desde tempos remotos. De acordo com Neto \& Gomes (2002), os processos históricos que levaram ao surgimento das $\mathrm{AD}$ antecedem suas aplicações nas empresas. Práticas como "a escolha de um cônjuge, o presentear um filho por mérito ou quaisquer gestos de reconhecimento dos indivíduos pelos membros do grupo social [...]" já eram constituídos de critérios para qualificação e reconhecimento promocional.

Com o passar do tempo, a intensificação das relações entre homem e trabalho (advindas do Capitalismo) levaram ao surgimento de meios que pudessem avaliá-los de maneira sistemática. Em 1842, o Congresso estadunidense aprovou uma lei que obrigava os setores administrativos a emitirem relatórios anuais para manutenção e verificação do rendimento de seus funcionários.

Em 1879, o departamento responsável pelo Sistema de Pensões dos EUA elaborou um sistema que tentava mensurar o desempenho de seus colaboradores pela contagem do número de erros que os mesmos cometiam anualmente. Um ano depois, o exército dos Estados Unidos criou um sistema de avaliação que acabou se propagando pelos demais departamentos. Desde então, organizações dos mais diversos tipos têm buscado maneiras de avaliar o desempenho de funcionários como uma forma de difundir seus valores e princípios de qualidade (CHIAVENATO, 1981).

Em geral, as Avaliações de Desempenho nas organizações são compostas pelos seguintes elementos: 1) avaliadores (pessoas ou setores responsáveis pela formulação, aplicação e acompanhamento dos testes); 2) avaliados (funcionários submetidos às avaliações); 3 ) métodos (conjunto de técnicas e ferramentas utilizadas durante todo o processo). Da mesma forma, também deve-se estar atento para as questões voltadas às estratégias, objetivos e recursos da empresa. Desta forma, pode-se garantir a veracidade dos resultados e sua efetividade na qualidade do trabalho (LUCENA, 1992). 
$16^{\circ}$ Ergodesign - Congresso Internacional de Ergonomia e Usabilidade de Interfaces Humano Tecnológica: Produto, Informações Ambientes Construídos e Transporte

$16^{\circ}$ USIHC - Congresso Internacional de Ergonomia e Usabilidade de Interfaces Humano Computador

CINAHPA | 2017 - Congresso Internacional de Ambientes Hipermídia para Aprendizagem.
Os avaliadores são considerados o principal componente deste conjunto, pois são eles quem irão determinar os métodos a serem utilizados durante a formulação, aplicação e análise dos resultados das avaliações. Fazem parte deste grupo os funcionários da própria organização ou, ainda, consultores externos contratados unicamente para este propósito. Ambos apresentam aspectos positivos e negativos, cabendo à empresa decidir qual tipo de avaliador é mais adequado à sua situação. Já os avaliados são todos aqueles submetidos às avaliações em si, sem que haja distinções entre cargos e funções. Os métodos são compostos por procedimentos e técnicas que ajudam a nortear as operações a serem realizadas, evitando-se possíveis erros e auxiliando a obtenção dos resultados desejados (NETO \& GOMES, 2002).

Segundo Bergamini e Beraldo (1988), os métodos de aplicação das Avaliações de Desempenho podem ser classificados entre os 3 seguintes grupos:

- "Avaliação direta - quem pratica a avaliação é o supervisor direto, representado pela chefia hierárquica ou funcional ligada ao avaliado. Esse método atribui ao supervisor direto a tarefa de emitir parecer sobre o pessoal que lhe cabe dirigir no dia-a-dia de trabalho;

- Avaliação conjunta - esse método traz intrinsecamente a possibilidade de participação, uma vez que o avaliador e o avaliado desde logo conversem sobre seu desempenho e, quando é o caso, preencham juntos a ficha de avaliação de desempenho. Trata-se de uma possibilidade de troca extremamente rica e que, quando o contexto organizacional permite, não deve ser desprezada;

- Auto-avaliação - é a possibilidade de avaliação que, ao longo do tempo, foi a menos utilizada, tornando-se mais conhecida e mais amplamente praticada recentemente, talvez de uns dez a quinze anos pra cá. Esse método implica uma participação mais ativa do avaliado." (BERGAMINI \& BERALDO, 1988).

Com relação aos seus objetivos, as Avaliações de Desempenho podem ser classificados conforme as seguintes áreas: treinamento (desenvolvimento e capacitação de funcionários); aumentos salariais e promoções a novos cargos; comunicação (diálogo e troca de informações entre diferentes setores e hierarquias); planejamento de recursos humanos (formulação de estratégias e gestão empresariais); e seus aspectos legais/jurídicos (ANDREASSI, 1994).

Para Bohlander et al (2003) uma dos principais benefícios atrelados às Avaliações de Desempenho é a sua capacidade de estabelecer relações de mútuo benefício entre os trabalhadores e as organizações. Considerando-se o fato de que estas são, em sua totalidade, constituídas por pessoas, torna-se evidente a necessidade de estarem sempre atentas às qualidades, dificuldades e necessidades de seus colaboradores, pois estes fatores irão influenciar diretamente no desempenho e resultados de suas respectivas atividades.

\subsection{Organizações e Microempresas}

As organizações podem ser entendidas como um sistema estruturado composto por pessoas.

Segundo Maximiano (1992), ela é "uma combinação de esforços individuais que tem por finalidade realizar propósitos coletivos. Por meio de uma organização, torna-se possível perseguir e alcançar objetivos que seriam inatingíveis para uma pessoa". Elas têm, por natureza, um caráter intermediário, onde o atendimento e a satisfação de seus clientes só ocorre mediante a elucidação de metas bem definidas, tornando-se possível o aproveitamento de recursos humanos para a elaboração de estratégias que irão viabilizar seu atingimento (CARAVANTES, 1997).

Para Asquini (2007), as empresas apresentam, de modo geral, quatro perfis que compreendem e conceituam suas atividades. São eles:

- Perfil Subjetivo - a empresa é representada como uma pessoa (o empresário, no caso) física ou jurídica que "exercita profissionalmente atividade econômica organizada com o fim da produção e da troca de bens ou serviços";

- Perfil Funcional - a empresa é vista como uma
Realização:

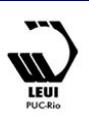

UNIVERSIDADE FEDERAL DE SANTA CATARINA 


\section{$16^{\circ}$ \\ ERGODESIGN USIHC CINAHPA}

$16^{\circ}$ Ergodesign - Congresso Internacional de Ergonomia e Usabilidade de Interfaces Humano Tecnológica: Produto, Informações Ambientes Construídos e Transporte

$16^{\circ}$ USIHC - Congresso Internacional de Ergonomia e Usabilidade de Interfaces Humano Computador

CINAHPA | 2017 - Congresso Internacional de Ambientes Hipermídia para Aprendizagem. "atividade empresarial dirigida a um determinado escopo produtivo", responsável pela fabricação e oferta de bens e serviços;

- Perfil Objetivo - a empresa representa um conjunto de bens patrimoniais destinados à prática de determinadas atividades comerciais;

- Perfil Corporativo - a empresa é composta por um número de pessoas unidas pelo alcance de objetivos em comum. Ou seja, ela é "formada pelo empresário e por seus prestadores de serviços".

Segundo Sales (2007), as empresas podem ser classificadas de acordo com os seguintes aspectos: "objetivos (comerciais, industriais, de prestação de serviços); tamanho (grande, média, pequena, micro); estrutura (individuais, coletivas, públicas, mistas); volume de trabalho interno (simples, complexas); e organização (linear ou militar, funcional, estado maior ou "staff").

Com relação às microempresas, deve-se, primeiro, entender as características que as distinguem das demais. De acordo com o Sebrae (2016), são consideradas microempresas toda e qualquer sociedade (empresária, simples ou individual de responsabilidade limitada) e empresário "devidamente registrados nos órgãos competentes, que aufira em cada ano calendário a receita bruta igual ou inferior a R \$360.000,00", atendo-se à Lei 123/06 do Simples Nacional para o enquadramento de Microempresas.

Para classificação do porte das empresas (para fins bancários, ações de tecnologia, exportação e afins), o SEBRAE também utiliza os seguintes critérios:

Para as indústrias

- Micro - até 19 empregados

- Pequena - de 20 a 99 empregados

- Média - 100 a 499 empregados

- Grande - mais de 500 empregados

Para comércio e serviços

- Micro - até 09 empregados

- Pequena - de 10 a 49 empregados
- Média - de 50 a 99 empregados

- Grande - mais de 100 empregados

Segundo Levitsky (1996), as fraquezas presentes nas microempresas dos países em desenvolvimento não são muito diferentes daquelas que ocorrem em países de primeiro mundo, variando apenas em grau de incidência. Para o autor, são constantes os problemas relacionadas à falta de habilidades gerenciais dos funcionários, utilização de equipamentos e maquinário obsoletos e acesso limitado a novos mercados e tecnologias procedimentais.

\section{Problemática}

Mediante a diversidade com a qual se é possível utilizar as Avaliações de Desempenho, elas acabam sendo definidas de acordo com as impressões individuais de autores distintos, o que, por vezes, pode acabar gerando ambiguidades e, inclusive, disparidades quanto às suas interpretações. Por este motivo, os presentes estudos têm como objetivo geral evidenciar as semelhanças entre os diversos conceitos atribuídos às Avaliações de Desempenho, bem como suas relações com a gestão estratégica das microempresas.

Para alcance desta meta, fez-se necessário o cumprimento dos seguintes objetivos específicos:

- Pesquisar referências bibliográficas para fundamentação do tema e problemática;

- Identificar e condensar as principais linhas de pensamento dos autores pesquisados;

- Analisar as relações entre os conceitos das AD e as especificidades das microempresas sob enfoque macroergonômico;

- Apresentar resultados e conclusão final provenientes das análises de dados para informatização e embasamento a estudos futuros.

\section{Procedimentos Metodológicos}

O método utilizado para a definição dos autores foi a Revisão Bibliográfica Sistemática, que consiste

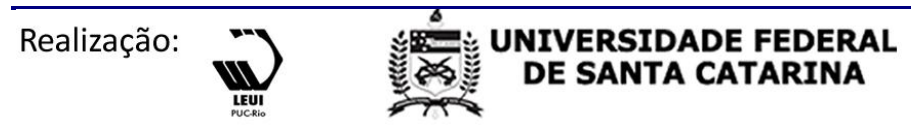




\section{$16^{\circ}$ \\ ERGODESIGN USIHC CINAHPA}

$16^{\circ}$ Ergodesign - Congresso Internacional de Ergonomia e Usabilidade de Interfaces Humano Tecnológica: Produto, Informações Ambientes Construídos e Transporte

$16^{\circ}$ USIHC - Congresso Internacional de Ergonomia e Usabilidade de Interfaces Humano Computador

CINAHPA | 2017 - Congresso Internacional de Ambientes Hipermídia para Aprendizagem. na seleção de critérios de busca específicos para inclusão e exclusão de dados que irão diretrizar a pesquisa (COOK; MULROW; HAYNES, 1997).

A escolha dos autores se deu conforme o número de citações nas bases de dados da Capes (periódicos), tendo-se como palavras-chave dos operadores lógicos para consulta: "Avaliação de Desempenho".

Quanto à definição dos parâmetros comparativos das análises entre os diferentes autores, foram utilizados os seguintes aspectos das Avaliações de Desempenho:

- Conceito (entendimento geral dos fundamentos que constituem a Avaliação de Desempenho);

- Objetivos (principais metas associadas à sua implementação nas organizações);

- Vantagens (benefícios associados às diferentes áreas de uma organização envolvidas no processo).

\section{Resultados (Características das AD)}

Abaixo, as conceituações e demais características das AD de acordo com seus respectivos autores, de acordo com o número de citações nas bases de dados pesquisadas.

\subsection{Autor 1 - CHIAVENATO, Idalberto}

- Conceito

A Avaliação de Desempenho é uma apreciação sistemática do comportamento da pessoa no cargo que ocupa, bem como de seu potencial de desenvolvimento. Toda avaliação é um processo para julgar ou estimular o valor, a excelência e as qualidades de uma pessoa.

- Objetivos

a) Permitir condições de medição do potencial humano no sentido de determinar sua plena aplicação;

b) Permitir o tratamento dos recursos humanos como importante vantagem competitiva da organização e cuja produtividade pode ser desenvolvida, dependendo, obviamente, da forma de administração;

c) Fornecer oportunidades de crescimento e condições de efetiva participação a todos os membros da organização, tendo em vista, de um lado, os objetivos organizacionais e, de outro, os objetivos individuais.

- Vantagens

a) Melhora o desempenho e mantém a força de trabalho;

b) Determina necessidades de treinamento e oportunidades de desenvolvimento pessoal;

c) Serve de base para promoções, transferências, desligamentos e aumentos salariais;

d) Auxilia nos processos de recrutamento, seleção, colocação e integração de funcionários;

e) Serve de mecanismo de retroação e comunicação (feedback).

\subsection{Autor 2-LUCENA, Maria Diva da Salete \\ - Conceito}

A Avaliação de Desempenho é a verificação formal e permanente dos resultados alcançados do trabalhador comparados com os padrões de desempenho estabelecidos pela organização.

\section{- Objetivos}

a) Definir e mensurar o grau de contribuição de cada empregado na consecução dos objetivos da empresa;

b) Subsidiar as ações de treinamento e desenvolvimento tendo em vista a capacitação profissional dos empregados;

c) Facilitar o planejamento de ações para corrigir desempenhos (readaptações, remanejamentos,
Realização:

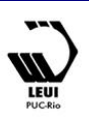


$16^{\circ}$ Ergodesign - Congresso Internacional de Ergonomia e Usabilidade de Interfaces Humano Tecnológica: Produto, Informações Ambientes Construídos e Transporte

$16^{\circ}$ USIHC - Congresso Internacional de Ergonomia e Usabilidade de Interfaces Humano Computador

CINAHPA | 2017 - Congresso Internacional de Ambientes Hipermídia para Aprendizagem. transferências, aspectos comportamentais, etc.);

d) Subsidiar os processos de promoção, progressão salarial e carreira profissional, que utilização os resultados da Avaliação de Desempenho de acordo com normas estabelecidas para este fim;

e) Possibilitar ao empregado a identificação e bisca dos meios necessários ao autodesenvolvimento, através da sua participação e conhecimento dos resultados da avaliação.

- Vantagens

a) Analisa as variáveis do ambiente organizacional que afetam positiva ou negativamente $o$ desempenho;

b) Promove a qualificação profissional e o desenvolvimento de habilidades dos empregados;

c) Antecipa as ações necessárias para evitar que o desempenho seja desviado dos resultados esperados.

d) Assegura que os desempenhos individuais e da equipe produzam o resultado esperado;

e) Fornece feedback ao funcionário sobre seu desempenho.

\subsection{Autor 3 - BERGAMINI, Cecilia Whitaker}

- Conceito

A Avaliação de Desempenho nas organizações constitui-se no veículo da estimativa de aproveitamento do potencial individual das pessoas no trabalho e, por isso, do potencial humano de toda a empresa.

\section{- Objetivos}

a) Revisar o cumprimento das metas ou atingimento de resultados;

b) Apreciar o comportamento da pessoa (a maneira como realiza seus objetivos); c) Avaliar o Potencial (estimar sobre os rumos que o indivíduo pode tomar na sua carreira dentro da organização).

- Vantagens

a) Seleção de Pessoal - representa uma das fontes mais objetivas e, por conseguinte, de maior segurança no tocante ao controle de validade do processo seletivo utilizado;

b) Treinamento e Desenvolvimento de Pessoal nenhuma outra fonte de levantamento de necessidades de treinamento é tão rica e segura quanto aquela representada pelas conclusões finais de avaliação de desempenho;

c) Administração Salarial - há numerosas organizações que utilizam a avaliação de desempenho com o único objetivo de recompensar financeiramente os esforços pessoais de seus empregados;

d) Movimentação de Pessoal - o tempo de função, o preparo pela experiência, as dificuldades de cada um, os problemas de produtividade e relacionamento, adicionados às necessidades da própria organização por seu crescimento, entre outros fatores, tornam necessária constante realocação dos recursos humanos disponíveis.

\subsection{Autor 4 - BOHLANDER, George}

- Conceito

As Avaliações de Desempenho são uma das ferramentas mais poderosas para a empresa manter e aumentar a produtividade, além de facilitar o cumprimento de metas estratégicas.

\section{- Objetivos}

a) Proporcionar discussões regulares entre funcionários e supervisores a respeito do desempenho e os padrões de desempenho;

b) Fornecer ao supervisor um meio de identificar os pontos fortes e fracos do desempenho dos funcionários; 
$16^{\circ}$ Ergodesign - Congresso Internacional de Ergonomia e Usabilidade de Interfaces Humano Tecnológica: Produto, Informações Ambientes Construídos e Transporte

$16^{\circ}$ USIHC - Congresso Internacional de Ergonomia e Usabilidade de Interfaces Humano Computador

CINAHPA | 2017 - Congresso Internacional de Ambientes Hipermídia para Aprendizagem. c) Fornecer ao supervisor um formato que lhe permita recomendar programas específicos para ajudar os colaboradores a aprimorarem seu desempenho;

d) Fornecer bases para recomendações salariais.

- Vantagens

a) Identifica metas e necessidades organizacionais de desenvolvimento;

b) Identifica necessidades de treinamento ao reconhecer os pontos fortes e fracos do indivíduo;

c) Auxilia os processos de remuneração e promoção de funcionários;

d) Viabiliza a documentação de decisões (retenções, rescisões, transferências e atribuições);

e) Fornece feedback de desempenho aos avaliados.

\section{Análise dos Resultados}

As análises referentes aos dados obtidos nas pesquisas foram realizadas de acordo com a ordem de relevância dos autores:

- Autor 1 - CHIAVENATO, Idalberto

Sua conceituação das AD sugere uma certa relatividade na interpretação do desempenho do trabalhador, uma vez que este só pode ser mensurado tendo-se como base seus resultados estimados previamente. Para Chiavenato, os objetivos das AD estão atrelados a fatores administrativos (visão, objetivos e estratégias da empresa), pois eles contribuem com a capacitação dos colabores e o envolvimento dos setores responsáveis pela implementação das avaliações.

- Autor 2 - LUCENA, Maria Diva da Salete

De modo semelhante a Chiavenato, Lucena sugere que os resultados do desempenho só podem ser mensurados quando comparados a metas previamente estabelecidas. A definição da contribuição do trabalhador na organização irá determinar as ações para com o mesmo (treinamento, promoções, aumentos salariais e planos de carreira) desde que o histórico de seu desempenho não oculte seus atuais resultados, sugerindo-se acompanhamentos constantes.

\section{- Autor 3 - BERGAMINI, Cecília Whitaker}

Bergamini afirma que o propósito das Avaliações de Desempenho está em aproveitar os potenciais individuais do trabalhador através da otimização da própria mão-de-obra. Para isto, é necessário que o gerente responsável também esteja apto a exercer sua função de avaliador corretamente, considerando as peculiaridades do indivíduo avaliado (sua personalidade, cargo/função e ambiente/local de trabalho).

\section{- Autor 4 - BOHLANDER, George}

Para Bohlander, a Avaliação de Desempenho é responsável pela produtividade e estratégias organizacionais através do incentivo e qualificação do funcionário. Este é reconhecido como um componente fundamental para o alcance das metas que garantem vantagens competitivas à empresa. Por este motivo, o acompanhamento constante de seu desempenho tem influência direta no atingimento das metas organizacionais.

\subsection{Principais convergências entre os autores}

Após a síntese dos principais itens referentes às linhas de pensamento dos autores, nota-se uma série de pontos em comum. São eles:

- Visão das Avaliações de Desempenho como ferramenta capaz de corrigir problemas (treinamento e realocação de funcionários) e reconhecer potenciais (promoções e aumentos salariais);

- Valorização de aspectos humanísticos (singularidades do trabalhador enquanto indivíduo), sabendo-se que o papel exercido pelo colaborador é fundamental para o sucesso da organização;

- Sistematização dos processos de avaliação são essenciais para sua correta formulação e 
$16^{\circ}$ Ergodesign - Congresso Internacional de Ergonomia e Usabilidade de Interfaces Humano Tecnológica: Produto, Informações Ambientes Construídos e Transporte

$16^{\circ}$ USIHC - Congresso Internacional de Ergonomia e Usabilidade de Interfaces Humano Computador

CINAHPA | 2017 - Congresso Internacional de Ambientes Hipermídia para Aprendizagem. implementação nas empresas.

Também é possível discernir as relações que as Avaliações de Desempenho têm com relação à gestão estratégica das microempresas, tendo-se em vista suas limitações:

- Atribuição significativa do sucesso organizacional à satisfação e produtividade do trabalhador, e não apenas a recursos financeiros e infraestruturais;

- Exxito nos processos de avaliação independem do perfil, porte e/ou de número de trabalhadores da empresa, desde que o avaliador e método escolhido relevem suas realidades financeira e tecnológica (interna e externamente).

\section{Conclusão}

Apesar de existirem diversos conceitos atribuídos às Avaliações de Desempenho, é possível perceber claramente que muitos de seus fundamentos são, de fato, complementares, pois não invalidam um ao outro.

Estes mesmos conceitos, além de propiciarem uma visão mais clara de todos os benefícios das avaliações (a curto, médio e longo prazo), também viabilizam o estudo de suas aplicações nas microempresas, uma vez que não são delimitadas as características que as mesmas devem apresentar, como, por exemplo: segmento, porte e recursos (financeiros, humanos e tecnológicos).

A macroergonomia aborda questões relacionadas a sistemas sociotécnicos que envolvem interações entre o homem e seu ambiente de trabalho. Por isso, tornando-se relevante observar o modo como os autores enfatizam os fatores humanos no atingimento de metas e obtenção de resultados satisfatórios para as organizações, em especial àquelas onde a produção de serviços e bens de consumo dependem quase que exclusivamente da realização de tarefas que exigem de seus colaboradores proatividade e produtividade.

Por fim, pode-se concluir que a valoração e valorização da força de trabalho dependem do grau de motivação em que esta se encontra, conferindose às organizações, mesmo que indireta e parcialmente, a tarefa de promover tais condições no âmbito laboral.

\section{Sugestões para Estudos Futuros}

Os presentes estudos também pretendem prover embasamentos informacionais considerados necessários para a realização de pesquisas futuras (a serem conduzidas por demais pesquisadores interessados no assunto) nas quais a temática e suas ramificações possam ser ainda mais aprofundadas.

Segue abaixo uma listagem de sugestões para pesquisas futuras:

- Análise dos fatores de influência na utilização de ferramentas de suporte durante a formulação e implementação das Avaliações de Desempenho;

- Realização de estudos de caso para comparação da efetividade de métodos de Avaliação de Desempenho específicos em empresas de diferentes portes e/ou segmentos;

- Verificação da implementação das Avaliações de Desempenho e os possíveis melhoramentos nas relações entre gerência e colaboradores da empresa.

\section{Referências Bibliográficas}

ASQUINI, A. Perfis da empresa. Revista de Direito Mercantil, São Paulo, v. 35, n. 104, 1996.

\section{ANDREASSI, T. Avaliação de Desempenho de profissionais técnicos: um estudo de casos. Dissertação (Mestrado) - Faculdade de Economia, Administração e Contabilidades. Universidade de São Paulo, 1994.}

BERGAMINI, C. W.; BERALDO, D. G. R.. Avaliação de desempenho humano na empresa. $4^{\mathrm{a}}$ ed. São Paulo: Atlas, 1983.

BOHLANDER, G. et al. Administração de Recursos Humanos. São Paulo: Pioneira Thomson Learning, 2003.

Realização:


$16^{\circ}$ Ergodesign - Congresso Internacional de Ergonomia e Usabilidade de Interfaces Humano Tecnológica: Produto, Informações Ambientes Construídos e Transporte

$16^{\circ}$ USIHC - Congresso Internacional de Ergonomia e Usabilidade de Interfaces Humano Computador

CINAHPA | 2017 - Congresso Internacional de Ambientes Hipermídia para Aprendizagem.
CARAVANTES, G. R. Administração e qualidade: a superação dos desafios. São Paulo: Makron Books, 1997.

CHIAVENATO, I. Administração de recursos Humanos. $2^{\text {a }}$ ed. São Paulo: Editora Atlas, 1981.

CHIAVENATO, I. Desempenho humano nas empresas: Como desenhar cargos e avaliar o desempe. $4^{a}$ ed. São Paulo: Editora Atlas, 1998.

CHIAVENATO, I. Gestão de pessoas: o novo papel dos recursos humanos na administração. Rio de Janeiro: Editora Campus, 1999.

\section{CHIAVENATO, I. Recursos humanos nas} empresas: como desenhar cargos e avaliar o desempenho. $5^{\text {a }}$ ed. São Paulo: Editora Atlas, 2001.

COOK, D. J.; MULROW, C. D.; HAYNES, R. B.. Systematic reviews: synthesis of best evidence for clinical decisions. Annals of internal medicine, $\mathrm{v}$. 126, n. 5, 1997.

FLEURY, M. T. L. A gestão de competência e a estratégia organizacional. In: FLEURY, M. T. (Coord.). As Pessoas na Organização. São Paulo: Gente, 2002.

IEA (International Ergonomics Association). Definition and Domains of Ergonomics. 2016. Disponível em: <http://www.iea.cc/whats/>. Acesso em 20 out. 2016.

GRILLO, A.N. Avaliação de Desempenho: Experiência brasileira na Administração Pública. In: Revista de Administração - USP. vol. 17, n. 1, 1981.

\section{LEVITSKY, J. Small business in transition} economies: promoting enterprise in Central and Eastern Europe and the former Soviet Union. Intermediate Technology Publications, 1996.

LIMA, G. B. C.; OLIVEIRA, C. G. A.; VEIGA, M. R. M. Implantação de um Sistema de Avaliação de Desempenho: Métodos e Estratégias. In: Revista de Administração - USP. vol. 31, n. 3, 1996.
LUCENA, M. D. da S. Avaliação de Desempenho. São Paulo: Editora Atlas, 1992.

\section{MAXIMIANO, A. C. A. Introdução à}

administração. $3^{\text {a }}$ ed., São Paulo: Editora Atlas, 1992.

NETO, A. S.; GOMES, R. M. Reflexões sobre a avaliação de desempenho: uma breve análise do sistema tradicional e das novas propostas. In: Revista Eletrônica de Ciência Administrativa, v. 1, n. 1, Janeiro-Junho, 2002.

RABAGLIO, M. O. Avaliação por Competência: ferramenta de remuneração ou de desenvolvimento? Rio de Janeiro: Qualitymark, 2010.

\section{SEBRAE. Critérios de Classificação de} Empresas. Disponível em:

<http://www.sebraesc.com.br/leis/default.asp?vcdt exto $=4154>$. 2016. Acesso em: 03 ago. 2016.

\section{Agradecimentos}

Agradecimentos joviais à família, amigos, orientadores, professores, colegas, órgãos e instituição de ensino (CNPq, CAPES e UDESC) que, juntos, sempre farão parte desta eterna jornada pelo conhecimento.

Realização:

